\title{
Biodegradable Microcapsules Loaded with Nerve Growth Factor Enable Neurite Guidance and Synapse Formation
}

\author{
Olga Kopach $1, *\left(\mathbb{D}\right.$, Anton M. Pavlov ${ }^{2,3}$, Olga A. Sindeeva ${ }^{2,4} \oplus$, Gleb B. Sukhorukov ${ }^{2,4, *}$ and Dmitri A. Rusakov ${ }^{1, *}$ \\ 1 Department of Clinical and Experimental Epilepsy, UCL Queen Square Institute of Neurology, \\ University College London, London WC1N 3BG, UK \\ 2 School of Engineering and Materials Science, Queen Mary University of London, Mile End Road, \\ London E1 4NS, UK; a.pavlov@qmul.ac.uk (A.M.P.); O.Sindeeva@skoltech.ru (O.A.S.) \\ 3 Remote Controlled Theranostic Systems Laboratory, Saratov State University, 83 Astrakhanskaya Street, \\ 410012 Saratov, Russia \\ 4 Center for Neurobiology and Brain Restoration, Skolkovo Institute of Science and Technology, 3 Nobel Street, \\ 143005 Moscow, Russia \\ * Correspondence: o.kopach@ucl.ac.uk (O.K.); g.sukhorukov@qmul.ac.uk (G.B.S.); \\ d.rusakov@ucl.ac.uk (D.A.R.)
}

Citation: Kopach, O.; Pavlov, A.M.; Sindeeva, O.A.; Sukhorukov, G.B.; Rusakov, D.A. Biodegradable Microcapsules Loaded with Nerve Growth Factor Enable Neurite Guidance and Synapse Formation. Pharmaceutics 2021, 13, 25. https: / dx.doi.org/10.3390/ pharmaceutics 13010025

Received: 22 November 2020 Accepted: 18 December 2020 Published: 25 December 2020

Publisher's Note: MDPI stays neutral with regard to jurisdictional claims in published maps and institutional affiliations.

Copyright: () 2020 by the authors. Licensee MDPI, Basel, Switzerland. This article is an open access article distributed under the terms and conditions of the Creative Commons Attribution (CC BY) license (https: / / creativecommons.org/ licenses/by/4.0/).

\begin{abstract}
Neurological disorders and traumas often involve loss of specific neuronal connections, which would require intervention with high spatial precision. We have previously demonstrated the biocompatibility and therapeutic potential of the layer-by-layer (LbL)-fabricated microcapsules aimed at the localized delivery of specific channel blockers to peripheral nerves. Here, we explore the potential of LbL-microcapsules to enable site-specific, directional action of neurotrophins to stimulate neuronal morphogenesis and synaptic circuit formation. We find that nanoengineered biodegradable microcapsules loaded with nerve growth factor (NGF) can guide the morphological development of hippocampal neurons in vitro. The presence of NGF-loaded microcapsules or their clusters increases the neurite outgrowth rate while boosting neurite branching. Microcapsule clusters appear to guide the trajectory of developing individual axons leading to the formation of functional synapses. Our observations highlight the potential of NGF-loaded, biodegradable LbL-microcapsules to help guide axonal development and possibly circuit regeneration in neuropathology.
\end{abstract}

Keywords: layer-by-layer (LbL) microcapsules; nerve growth factor (NGF); axon guidance

\section{Introduction}

The depletion of endogenous growth factors in the adult brain has been associated with numerous neurodegenerative conditions that can lead to severe neurological and psychiatric disorders [1-3]. Among at least 50 identified growth factors in the nervous system, several are considered essential for survival, maintenance, and regeneration of nerve cells. These include nerve growth factor (NGF), brain-derived neurotrophic factor (BDNF), and glial cell-derived neurotrophic factor (GDNF). Supplying neurotrophic agents to specific neuronal subpopulations that undergo degeneration produced therapeutic effects, as documented by clinical trials dealing with Alzheimer's and Parkinson's diseases [4,5]. Several strategies have been attempted to help deliver NGF into the brain [6], aiming to overcome the undesired concomitants of systemic application, such as limited blood-brain barrier penetration or severe side effects. The viral vector-mediated gene therapy could potentially target identified neuronal populations but once delivered it could not be easily terminated, thus raising major safety issues. As an alternative route, cell-based approaches have been tried, such as transplanting NGF-secreting induced pluripotent stem cell (iPSC)-derived neurons into the damaged brain [7,8]. Although this method generates sustained endogenous production of NGF for up to a few months, it consistently showed a low cell survival rate following transplantation. An elegant innovative approach combining pharmaceutical and material sciences has been attempted, by encapsulating 
the NGF-secreting iPSC-derived cells, aiming to protect them from the immune response following transplantation [9-12]. Although the safety of this platform was confirmed, the NGF secretion level remained too low in half of the cohort [13].

An alternative strategy sought the encapsulation of exogenous NGF, to enable its prolonged release within the targeted area. Numerous studies have been carried out exploring different types of the cargo system, including biodegradable poly-lactic-coglycolic-acid (PLGA) microspheres [14-17] and nanoparticles made from natural polymer chitosan [18,19], gelatin [20,21], or collagen [22]. Most of these methods have focused on the peripheral nervous system or immortalized cell lines in vitro. The efficiency of the encapsulation technology and its applications with respect to central neurons has thus remained poorly understood. Here, we sought to test the effects of encapsulated NGF on the morphogenesis of central neurons, by exploring microcapsules that are nanoengineered from biodegradable materials, poly-L-arginine and dextran [23-25] using the layer-by-layer $(\mathrm{LbL})$ technique $[26,27]$. We have previously demonstrated biocompatibility, and key properties of release and biodegradation for these LbL-fabricated capsules, both in acute tissue slices and up to two weeks in free-behaving rodents, with the potential therapeutic efficacy as a local source of anaesthetics, and no detectable adverse effects [24]. This technique enables control over the capsule size and allows for encapsulation of various cargos, of a medium to high molecular weight. It also provides the possibility to set key properties of cargo storage and release. The established properties of LbL-microcapsules make this system potentially well-suited for the delivery of NGF to selected populations of brain neurons. To understand its potential, we, therefore, encapsulated NGF within the core of LbL-microcapsules and explored the effect of microcapsules on the morphogenesis of hippocampal neurons in vitro.

\section{Materials and Methods}

\subsection{Fabrication of Microcapsules Carrying NGF}

Polyelectrolyte-based microcapsules were fabricated using the LbL-assembly technique [28,29]. Briefly, $\mathrm{CaCO}_{3}$ microspheres with co-precipitated neurotrophin NGF were used as sacrificial templates. To this end, $1 \mathrm{~mL}$ of $0.33 \mathrm{M} \mathrm{Na}_{2} \mathrm{CO}_{3}$ was added to $1 \mathrm{~mL}$ of $0.33 \mathrm{M} \mathrm{CaCl}_{2}$ with $40 \mu \mathrm{g}$ NGF supplemented with $200 \mu \mathrm{g}$ bovine serum albumin (BSA) while stirring vigorously. BSA is widely used as an inert filler, for co-encapsulation with small quantities of biologically active substances, particularly with growth factors [30]: it acts as a protective agent and protein stabilizer [31]. As shown earlier for fibroblast grow factor in polyelectrolyte microcapsules, when co-encapsulated with BSA growth factors display more efficient immobilization and preservation of biological activity [32] After the successful synthesis of the cores (verified by optical microscopy), the templates were washed with $\mathrm{ddH}_{2} \mathrm{O}$ (by 3 steps of centrifugation/resuspension), and layers were assembled using the procedure as we have previously described in detail [24]. Shells were assembled of 3 bilayers of positively charged poly-L-arginine (PArg) and oppositely charged dextran sulfate sodium salt (DS), with the resulting shell structure [PArg/DS $]_{3}$. Both polyelectrolytes were adsorbed from $2 \mathrm{mg} / \mathrm{mL}$ solutions in $0.15 \mathrm{M} \mathrm{NaCl}$. At the final step, the $\mathrm{CaCO}_{3}$ cores were dissolved in $0.2 \mathrm{M}$ EDTA ( $\mathrm{pH} 6.5$ with $\mathrm{NaOH}$ ).

\subsection{Materials}

For the microcapsule fabrication purposes, all polyelectrolytes and other chemicals, including PArg, DS, BSA, NGF- $\beta$ (molecular weight $13.5 \mathrm{kDa}$ ), and all salts were purchased from Sigma-Aldrich (Gillingham, UK).

A hemocytometer for counting the number of microcapsules and freshly isolated hippocampal neurons was purchased from Labtech International (Heathfield, UK). For determining protein amount, Bradford assay kit was purchased from Sigma-Aldrich (Gillingham, UK). NeuroBasal A medium and B27 supplement were purchased from ThermoFisher Scientific (Hemel Hempstead, UK). The FM1-43 dye (N-(3-Triethylammoniumpropyl)-4-(4- 
(Dibutylamino)Styryl) Pyridinium Dibromide) and TRITC (tetramethylrhodamine) were also purchased from ThermoFisher Scientific (Hemel Hempstead, UK).

\subsection{Encapsulation Efficiency}

The amount of NGF per capsule was estimated based on the amount of co-loaded BSA in a similar encapsulation protocol, as described in detail previously [23,33]. BSA encapsulation ratio was $\sim 67 \%$, as we have determined with the Bradford protein assay using a Lambda 950 UV/VIS spectrophotometer (PerkinElmer, Beaconsfield, UK). Accordingly, the amount of NGF encapsulated per capsule could be estimated as $\sim 0.27 \mathrm{pg}$, which, upon release, should fall within a wide range of functionally relevant NGF concentrations [34,35].

\subsection{Scanning Electron Microscopy (SEM)}

To visualize fabricated microcapsules, we used scanning electron microscopy (SEM; FEI, Inspect-F, Hillsboro, OR, US) to ensure the structural appropriateness of our samples. To this end, a droplet of dispersing suspension of microcapsules was plated on a glass slide attached to the sample holder, then dried and sputtered with gold (Figure 1c,d). SEM was carried out at accelerating voltage of $10 \mathrm{kV}$ and a working distance of $10 \mathrm{~mm}$.

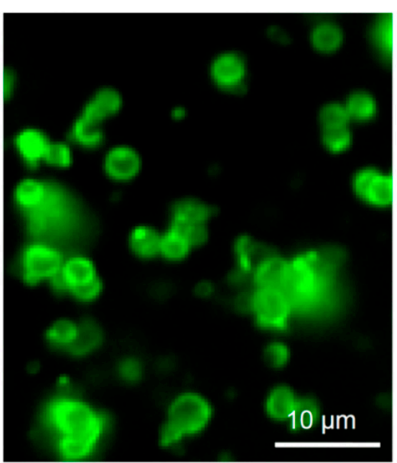

(a)

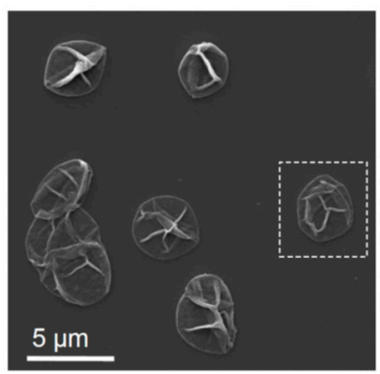

(c)

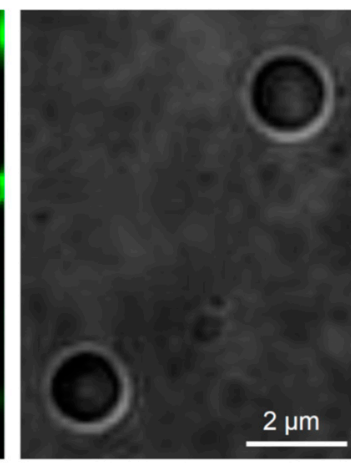

(b)

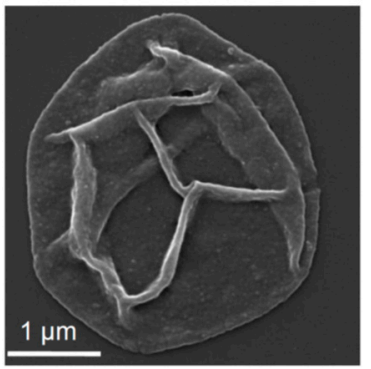

(d)

Figure 1. LbL-microcapsules carrying NGF. (a) An example of LbL-microcapsules in a suspension (epifluorescence of FITC conjugated to the microcapsule shell). (b) A DIC image of microcapsules at higher magnification. (c) SEM images of LbL-microcapsules dried and sputtered with gold. (d) Dotted rectangle regions in (c) shown at higher magnification.

\subsection{Primary Nerve Cell Cultures}

Hippocampal neurons were isolated from the Sprague-Dawley rat pups (P0 to P2 day-old) in accordance with the European Commission Directive (86/609/EEC) and the United Kingdom Home Office (Scientific Procedures) Act (1986), using animal protocols adapted in-house [36,37]. Neurons were cultured in a NeuroBasal A/B27-based medium on a rat astrocyte feeder layer at $37^{\circ} \mathrm{C}$ in a humidified atmosphere containing $95 \% \mathrm{O}_{2}$ and $5 \% \mathrm{CO}_{2}$ as we have described in our previous work [24]. We purposely maintained the low-density cultures to foster growth of developing hippocampal neurons with a polarized morphology [38]. For the low-density cultures, hippocampal neurons were plated at a low 
density, $\sim 20,000$ cells per coverslip. Neuronal morphology was assessed for individual cells at earlier developmental stages (from a few hours after plating to up to one week).

\subsection{Introducing Encapsulated NGF to Neuronal Cultures}

Microcapsules carrying NGF were added to the cultures shortly after plating cells on glass coverslips, at $1.5-2 \mathrm{~h}$ post-plating. To this end, an aliquot of freshly made microcapsules, re-suspended in a culture medium, was gently added at a total volume of $50 \mu \mathrm{L}$ into the well containing plated neurons. This amounted to $\sim 2.5 \times 10^{6}$ microcapsules per well; accordingly, the amount of encapsulated NGF added could be estimated as $670-680 \mathrm{ng} / \mathrm{mL}$. Neuronal cultures with NGF were incubated at $37^{\circ} \mathrm{C}\left(95 \% \mathrm{O}_{2} / 5 \% \mathrm{CO}_{2}\right)$ and cell morphology was systematically examined at $6.5 \mathrm{~h}, 24 \mathrm{~h}$, and $7 \mathrm{~d}$ of incubation with encapsulated NGF.

\subsection{Assessment of Neuronal Morphology and the Neurite Outgrowth Rate}

Neuronal morphology was assessed at different time-points after incubation with encapsulated NGF. For live imaging, a coverslip with cultured cells was placed in a recording chamber mounted on the stage of an Olympus BX51WI upright microscope (Olympus, Japan) equipped with a LUMPlanFI/IR $40 \times 0.8$ objective, tuned for infrared differential interference contrast (DIC) imaging. Cells were continuously superfused with a Ringer solution, a physiological buffer containing (in $\mathrm{mM}$ ) $126 \mathrm{NaCl}, 3 \mathrm{KCl}, 2 \mathrm{MgSO}_{4}$, $2 \mathrm{CaCl}_{2}, 26 \mathrm{NaHCO}_{3}, 1.25 \mathrm{NaH}_{2} \mathrm{PO}_{4}, 10 \mathrm{D}$-glucose, continuously bubbled with $95 \% \mathrm{O}_{2}$ and $5 \% \mathrm{CO}_{2}$ (pH 7.4; 300-310 mOsmol). Imaging was carried out using a Photometrics Evolve 512 EMCCD camera (Cairn Research, Faversham, UK) at a frame mode of $512 \times 512$ pixels, using various digital zooms. A Lumen Dynamics X-Cite 120Q lamp (Feasterville, PA, USA) was used as a light source to visualize microcapsules by TRITC (or FITC) fluorescence conjugated to their shell (Figure 1a). Images of individual hippocampal neurons (100$150 \mathrm{~nm} /$ pixel) were acquired using Micromanager 4.1 software (NIH, Bethesda, MD USA).

To quantitatively compare morphological parameters among experimental groups, the lengths and branching order of neurites were documented at the corresponding timepoints in control (untreated) cultures and those supplemented with encapsulated NGF. Neurites were traced manually, at varied magnification, categorized off-line for the primary neurites, secondary-order, and tertiary branches, and quantified using a NeuronJ plugin of ImageJ software (NIH, Bethesda, MD, USA).

\subsection{Visualizing Functional Synapses with FM1-43 Dye}

To confirm axonal development and formation of functional neural connections, we visualized functional synapses using a well-rehearsed method based on the fluorescent lipophilic dye FM1-43, in line with the protocol established by us earlier [39]. FM1-43 binds to cell membranes, and during active neurotransmission is taken up during the endocytosis phase of vesicle recycling, thus filling presynaptic terminals with fluorescing vesicles [40]. To enable this protocol, we added $20 \mu \mathrm{M}$ FM1-43 dye to cultured neurons and depolarized hippocampal neurons using bath application of $50 \mathrm{mM} \mathrm{KCl}$ in a HEPESbased physiological buffer for 1-2 min, thus triggering massive synaptic activity. This was followed by washing out all externally exposed FM1-43. Experiments were performed in a HEPES-based physiological buffer containing (in $\mathrm{mM}$ ) $135 \mathrm{NaCl}, 5 \mathrm{KCl}, 2 \mathrm{CaCl}_{2}, 2 \mathrm{MgCl}_{2}$, 10 HEPES, 10 glucose ( $\mathrm{pH}$ 7.4). Images were acquired using Micromanager 4.1 software (NIH, Bethesda, MD, USA) and analyzed off-line, using a freely available ImageJ software (NIH, Bethesda, MD, USA).

\subsection{Statistics}

We routinely presented the data as mean \pm standard error of the mean (s.e.m.), with $n$ referring to the number of cells analyzed within experimental groups. As the sample size was consistently above 20 , the normality test had no practical purpose as the Central Limit Theorem would predict the Gaussian distribution of the mean. Because we considered 
parameter variability either among individual cells or among individual neurites, with no biological hypotheses pertaining to the multi-factorial effects, we formed and compared the samples accordingly. The Student's t-test (two-tailed unpaired) was used to determine the statistical difference between such groups. Testing was carried out using OriginPro (OriginLab, Northampton, MA, US) and Excel software packages. The null hypothesis rejection level at $p<0.05$ was considered statistically significant.

\section{Results}

\subsection{Microcapsules}

To visualize microcapsules in the light microscope, the fluorescently labelled TRITCor FITC-conjugated polymer (commercially available FITC-labelled poly-L-lysine was used instead of PArg in the latter case) was utilized for the third-layer fabrication (Figure 1a,b).

Microcapsules had an average diameter of 2-3 $\mu \mathrm{m}$ (Figure 1a,b), and the nanoscopic appearance of their thin shells could be revealed by scanning electron microscopy (SEM; Figure $1 c, d)$. The number of microcapsules in a freshly prepared suspension was $~ 50$ $\times 10^{6} \mathrm{~mL}^{-1}$, as determined using a haemocytometer, with a total sample volume of $2 \mathrm{~mL}$. The suspension of microcapsules in $\mathrm{ddH}_{2} \mathrm{O}$ was stored at $4{ }^{\circ} \mathrm{C}$ and re-suspended immediately before supplementing to neuronal cultures.

\subsection{Encapsulated NGF Boosts the Neurite Outgrowth Rate}

To explore the effects of encapsulated NGF, we employed low-density neuron-astrocyte co-cultures, which provide favourable physiological conditions for synapse formation and function. In addition, in low-density neuronal cultures, hippocampal neurons develop with clearly polarized morphology [38], which facilitates quantitative assessment of neuronal development across its distinct stages. Cultured hippocampal neurons were assessed individually for their morphology, at several stages of development, either in the presence of LbL-microcapsules loaded with NGF or in the age-matched control (untreated) cultures.

In control co-cultures, nerve cells displayed a prompt morphological development, which was consistent with the established developmental stages in culture [38,41]. The vast majority of neurons had several clearly distinguishable small processes as early as $6.5 \mathrm{~h}$ after plating (developmental stages 1 and 2, in accord with [38]). Within the first $24 \mathrm{~h}$, all examined neurons exhibited well-formed polarity and numerous extended neurites (developmental stages 2 and 3; see below). We next measured (i) the total accumulated length of all neurites (dendrites and axons), and (ii) the mean neurite length per cell, in control cultures (Figure 2a) and in those containing NGF-loaded LbL-microcapsules (Figure 2b).

We found that encapsulated NGF markedly boosted the development of hippocampal neurons. At $6.5 \mathrm{~h}$ after plating, the total length of neurites was $58 \pm 4.9 \mu \mathrm{m}$ in control (mean \pm s.e.m., here and thereafter; $\mathrm{n}=60$ neurons, 331 neurites), whereas in the presence of NGF-loaded microcapsules it was $82 \pm 14.6 \mu \mathrm{m}$ ( $\mathrm{n}=21$ neurons, 104 neurites), an increase of $\sim 41 \%$. In most cases, the outgrowing neurites were directed towards the clusters of microcapsules, rather than into an arbitrary direction (Figure 2b). The role of glia in mediating NGF action in cultures was previously ruled out [42], thus pointing to the encapsulated NGF as a direct effector. The boosting effect of encapsulated NGF, as opposed to the presence of capsules in the medium, was confirmed by its local nature: only neurons growing within $\sim 50 \mu \mathrm{m}$ of the NGF-loaded microcapsules (termed 'local neurons' thereafter) exhibited elongated neurites. The total length of neurites almost doubled in these local neurons ( $\mathrm{n}=59$ neurites in 10 neurons; $p<0.05$ compared to control; Figure $2 \mathrm{c}$ ). There was no significant difference in the total neurite length between neurons located $>50 \mu \mathrm{m}$ from microcapsules (termed 'non-local neurons' thereafter; $44 \pm 7.9 \mu \mathrm{m}, \mathrm{n}=45$ neurites in 11 neurons) and those in control cultures $(p<0.05$; Figure $2 \mathrm{c})$. Correspondingly, the mean neurite length was also increased in test cultures: at $6.5 \mathrm{~h}$ post-plating, it was $16 \pm 1.7 \mu \mathrm{m}(\mathrm{n}=21$ cells, $p<0.05)$ compared to $12 \pm 0.9 \mu \mathrm{m}(\mathrm{n}=60$ cells $)$ in control cultures 
(Figure 2d). Again, only local neurons $(\mathrm{n}=10)$ exhibited the increase $(p<0.001$ compared to control; Figure 2d).

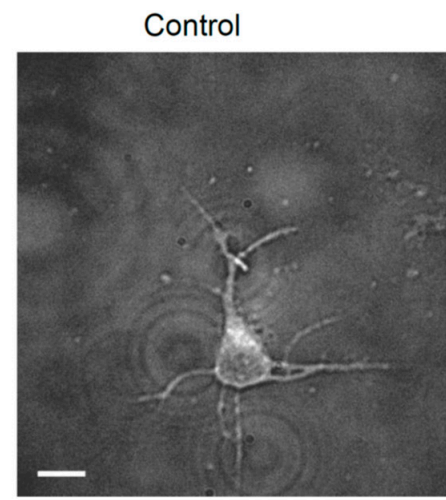

(a)

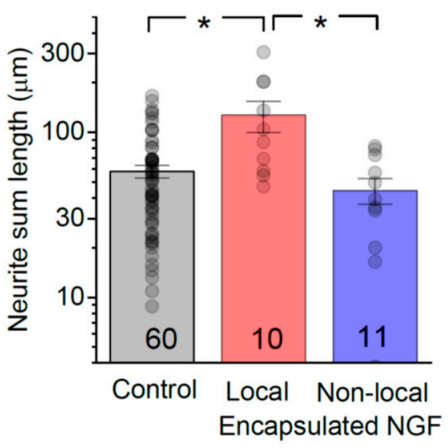

(c)

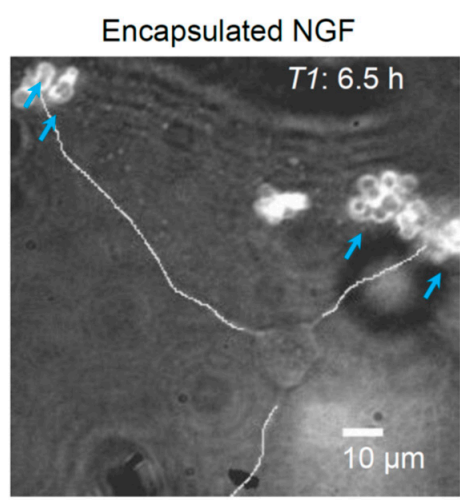

(b)

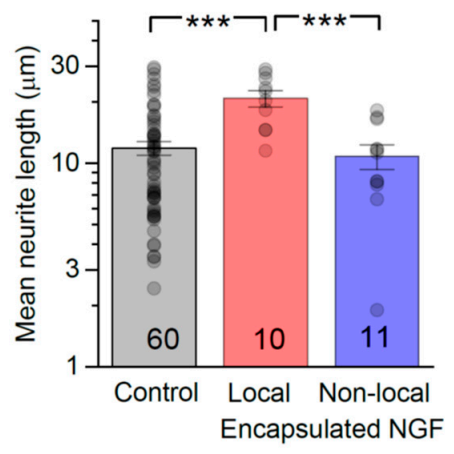

(d)

Figure 2. Encapsulated NGF boosts neurite outgrowth in developing hippocampal neurons in vitro. (a) A snapshot of developing hippocampal neurons, at $6.5 \mathrm{~h}$ after plating, in control conditions. (b) As in (a) but in the presence of NGF-loaded LbL-microcapsules; blue arrows, clusters of microcapsules labelled by TRITC; merged DIC and TRITC fluorescence channels; line-traced neurites illustrate neurite length measurement in individual cells. (c) Statistical summary of total neurite length (sum of individual neurite lengths) per neuron, $6.5 \mathrm{~h}$ after plating, in control conditions (no microcapsules), and in the presence of encapsulated NGF for local $(<50 \mu \mathrm{m}$ from capsules) and non-local $(>50 \mu \mathrm{m}$ away) cells, as indicated; numbers of cells shown. Dots, individual cell data; bars, mean \pm s.e.m; * $p<0.05$ (two-tailed unpaired $t$-test); ordinate, log scale. (d) Statistical summary for the mean neurite length per individual cell; ${ }^{* * *} p<0.001$ (two-tailed unpaired t-test); other notations as in (c).

At this development stage, the neurite outgrowth rate was $\sim 1.8 \mu \mathrm{m} \mathrm{h}^{-1}$ in control neurons, but $\sim 3.2 \mu \mathrm{m} \mathrm{h}^{-1}$ in local neurons, an increase of $\sim 78 \%$ (Figure $3 \mathrm{a}$ ). The neurite outgrowth rate remained unchanged $\left(\sim 1.7 \mu \mathrm{m} \mathrm{h}^{-1}\right)$ in non-local neurons (Figure 3a).

At $24 \mathrm{~h}$ after plating, cell neurites displayed a clear trajectory preference towards NGF-loaded capsules, which appeared to guide and accelerate their growth (Figure 3b). The total length of neurites in our control co-cultures was $125 \pm 7 \mu \mathrm{m}(\mathrm{n}=489$ neurites in 78 neurons; Figure 3c), thus displaying a clear developmental advantage over neuronal mono-cultures explored earlier (developmental stages 2 and 3 [38]). In the presence of encapsulated NGF, neurite outgrowth was boosted further still: the total neurite length increased by $\sim 26 \%$ ( $n=555$ neurites in 86 neurons, $p<0.01$ compared to the age-matched control; Figure 3c). The mean neurite length was also increased, by a similar degree (a $\sim 21 \%$ increase, $p<0.01$ compared to control; Figure 3c). Such prompt elongation led to almost all neurites eventually appearing within $50 \mu \mathrm{m}$ to microcapsule clusters, making further separation of 'local' and 'non-local' neurons infeasible. 


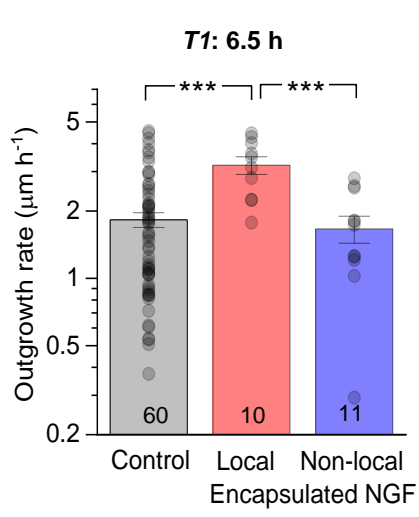

(a)

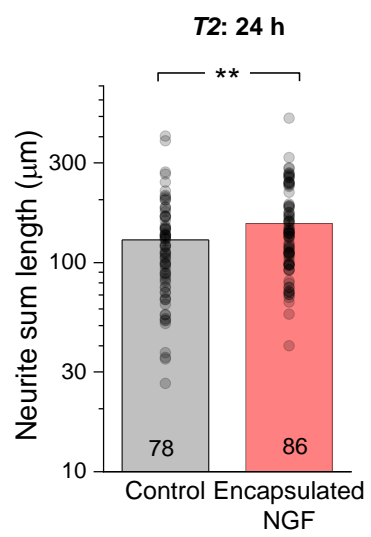

(c)

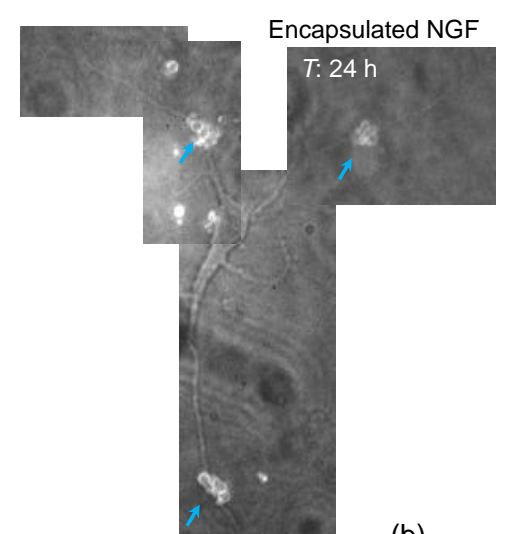

(b)

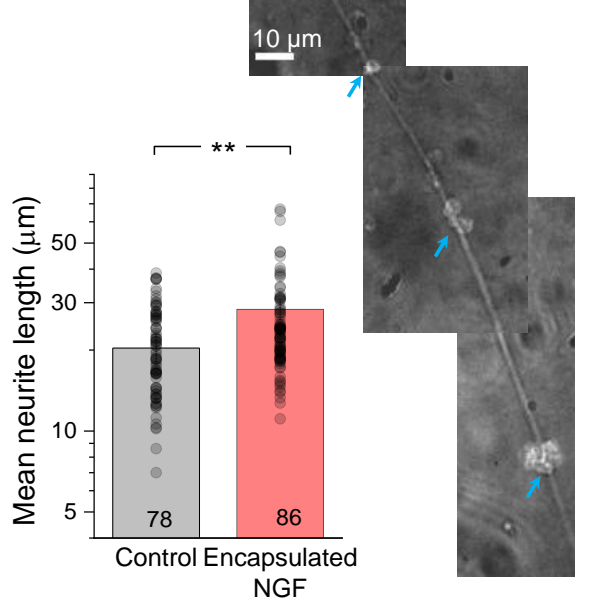

Figure 3. Encapsulated NGF elevates the neurite growth rate. (a) Average neurite length and the estimated outgrowth rate in control conditions and in the presence of encapsulated NGF for local ( $<50 \mu \mathrm{m}$ away from capsules) and non-local ( $>50 \mu \mathrm{m}$ away) cells, as indicated. (b) A snapshot of a pyramidal-like hippocampal neuron at $24 \mathrm{~h}$, with the growth trajectory of its main neurites directed by the clusters of NGF-releasing capsules (blue arrows; TRITC microcapsule labelling). Image, merged DIC and TRITC fluorescence channels (grey-level). (c) Statistical summary of the total (sum) neurite length (left) and mean neurite length (right) per individual neuron, at $24 \mathrm{~h}$ post-plating in control cultures and in the presence of encapsulated NGF. Dots, individual cell data; bars, mean \pm s.e.m; numbers of analysed cells shown; ${ }^{* *} p<0.01,{ }^{* * *} p<0.005$ (two-tailed unpaired $t$-test); ordinate, $\log$ scale.

After $>24$ h of incubation with NGF-loaded microcapsules, hippocampal neurons could be morphologically classified as ones reaching the developmental stages 4 and 5 ('dendritic outgrowth' and 'maturation' [38]). At this stage, the growing neurites become overlapped and intermingled, making the identification of individual neurites no longer feasible for the present analyses.

\subsection{Encapsulated NGF Enhances Neurite Branching}

We next examined whether encapsulated NGF could influence branching of elongated neurites, a key element in the formation of axons and dendrites. Individual hippocampal neurons were examined for the length of primary neurites, followed by the secondary and tertiary branches, if any (Figure 4a). At $6.5 \mathrm{~h}$ post-plating, cells had predominantly primary neurites, with few secondary-order branches and a rare occurrence of tertiary branches. Overall, the mean length was $\sim 11.4 \mu \mathrm{m}$ for the primary neurites $(\mathrm{n}=255)$ and $\sim 6.3 \mu \mathrm{m}$ for the secondary-order branches $(n=73$; Figure $4 b)$. In the presence of encapsulated NGF, hippocampal neurons developed, over the same period $(6.5 \mathrm{~h})$, both primary and 
secondary-order branches (both to a greater length than control), and even a few tertiary branches. Again, these acceleration effects were seen only in local neurons $(<50 \mu \mathrm{m}$ from microcapsules). The mean length of primary neurites was $\sim 23.2 \mu \mathrm{m}$ in local neurons compared to $\sim 11.4 \mu \mathrm{m}$ in control neurons $(p<0.001)$, and $\sim 13.7 \mu \mathrm{m}$ in non-local $(>50 \mu \mathrm{m}$ away from microcapsules) neurons ( $p<0.01$ compared to local neurons in the same culture). Correspondingly, the secondary-order neurite mean length was $\sim 17.9 \mu \mathrm{m}$ in local neurons compared to $\sim 6.3 \mu \mathrm{m}$ in control cultures $(p<0.01)$, and to $\sim 5.8 \mu \mathrm{m}$ in non-local neurons in the same culture (Figure $4 b$ ).

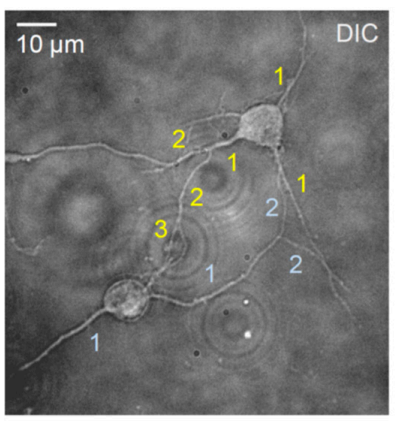

(a)

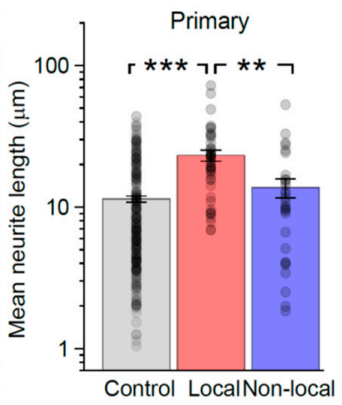

Control LocalNon-local

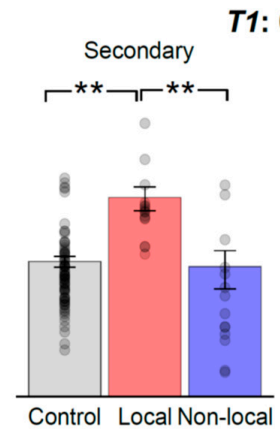

(b)

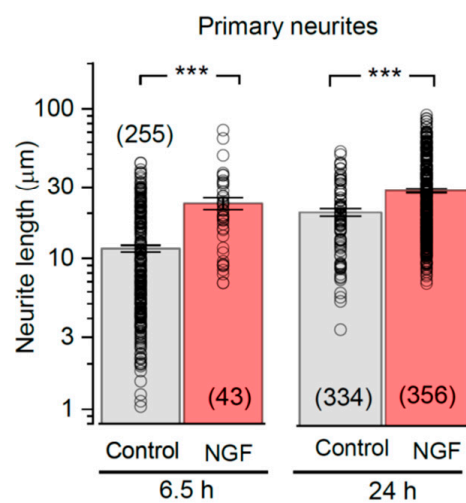

(c)

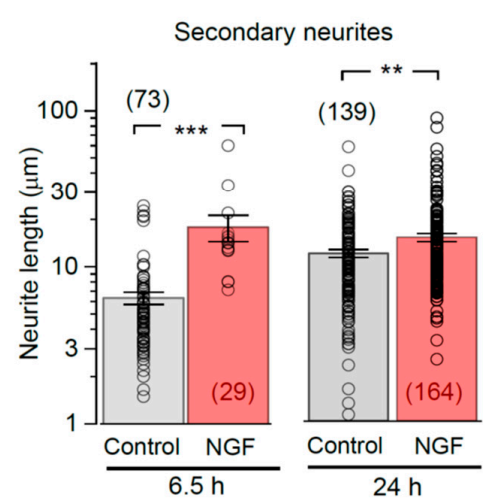

(d)

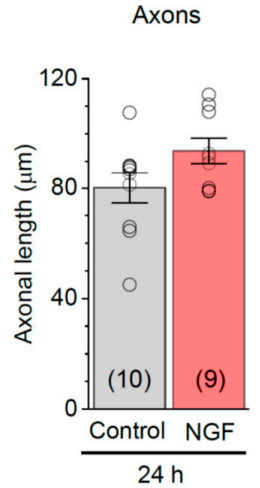

(e)

Figure 4. Encapsulated NGF boosts neurite branching. (a) Example (DIC channel) of two hippocampal neurons at $6.5 \mathrm{~h}$ post-plating in neuron-astrocyte co-culture, with the primary, secondary, and tertiary neurites as indicated (1, 2, and 3, respectively). (b) Statistics for individual neurite lengths, at various branch order, in control and in the presence of encapsulated NGF, for local $(<50 \mu \mathrm{m}$ from capsules) and non-local $(>50 \mu \mathrm{m})$ neurons, as indicated. Dots, neurite measurements pooled for individual cells; bars, mean \pm s.e.m.; ${ }^{*} p<0.05$; ${ }^{* *} p<0.01,{ }^{* * *} p<0.001$ (two-tailed $t$-test). (c,d) Statistical summary for the length of primary (c) and secondary branches (d) at $6.5 \mathrm{~h}$ and $24 \mathrm{~h}$ post-plating in control and in the presence of encapsulated NGF, as indicated. Dots, individual neurite measurements; bars, mean \pm s.e.m.; ${ }^{* *} p<0.01,{ }^{* * *} p<0.001$ (two-tailed t-test). (e) Statistics for the length of individual axons, as identified at $24 \mathrm{~h}$ post-plating, in control and in the presence of NGF-loaded microcapsules, as indicated.

After $24 \mathrm{~h}$ of incubation with encapsulated NGF, the mean neurite length increased for both primary (by $\sim 22 \%, p<0.001$ ) and the secondary-order branches (by $\sim 23 \%, p<0.01$ ), as compared to the age-matched neurons in control (Figure $4 \mathrm{c}, \mathrm{d}$ ). At that time point, we could morphologically distinguish the main axonal branches, as opposed to dendrites, in accord with morphological criteria established by us earlier [43]. The mean axonal length was $80 \pm 5 \mu \mathrm{m}$ ( $\mathrm{n}=10$ neurons) in control but appeared to increase to $94 \pm 5 \mu \mathrm{m}$ in the presence of encapsulated NGF ( $n=9$ cells, $p=0.07$; Figure 4e). 


\subsection{Neurons Cultured with Encapsulated NGF Form Functional Synapses}

To test whether the axonal development of hippocampal neurons in the presence of encapsulated NGF leads to functional synaptic connections between neurons, we carried out imaging of functional synapses in live hippocampal neurons using the fluorescent styryl dye FM1-43, the approach we validated earlier [39] (Figure 5a).
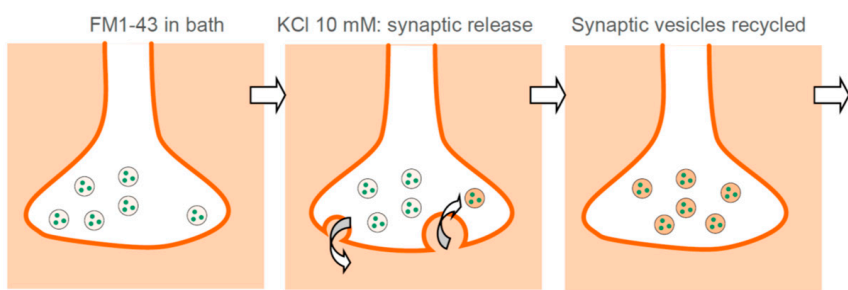

(a)

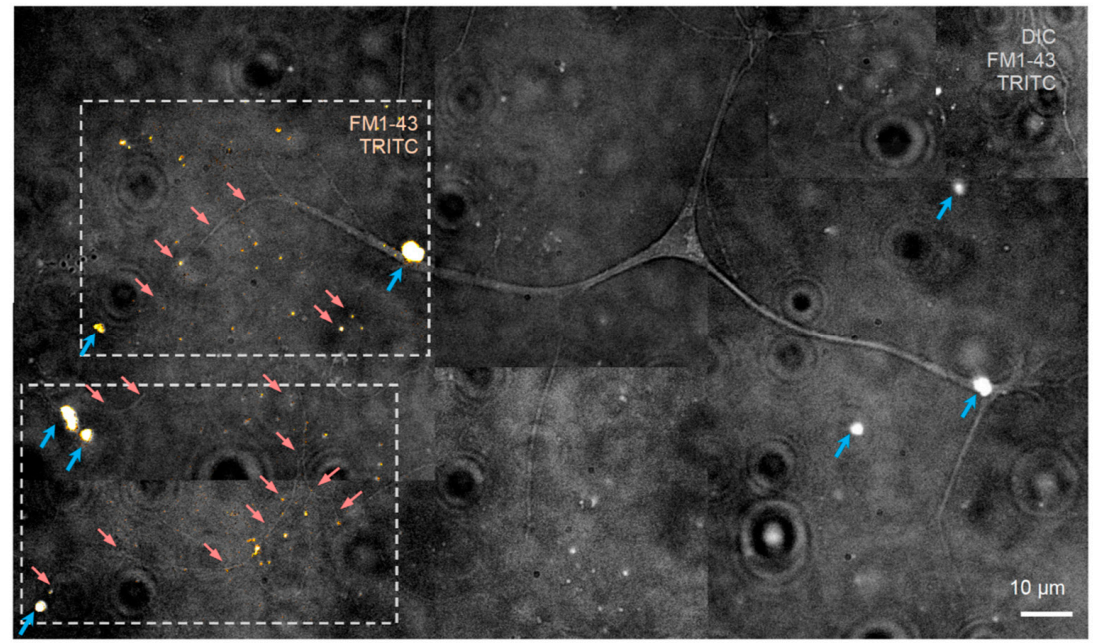

(b)

Figure 5. Neurites of hippocampal neurons are guided towards encapsulated NGF and form functional synapses. (a) A diagram sequence explaining fluorescence imaging of functional synaptic connections in cultured neurons using the fluorescent styryl dye FM143. The dye is washed in the bath, the active release of synaptic vesicles is activated by $50 \mathrm{mM} \mathrm{KCl}$ (bath application for $1 \mathrm{~min}$ ), the recycled vesicles take up and store the dye inside the axonal terminal, and the external FM1-43 fraction is washed out leaving detectable fluorescence inside active synapses. (b) One neuron example in neuron-astrocyte co-culture, with neuronal main and smaller processes growing towards clusters of NGFreleasing LbL-microcapsules at 7 days in vitro. Grey-scale image, merged DIC, TRITC, and FM1-43 fluorescence; red arrows, examples of neurites growing towards clusters of LbL-microcapsules (blue arrows, TRITC labelling); dotted frames, two ROIs illustrating fluorescence of TRITC and FM1-43 fused with DIC image to highlight the FM1-43 labelled functional synapses (orange spots) revealed after $\mathrm{KCl}$ application.

In brief, we bath applied FM1-43 and depolarized cultured neurons with highpotassium ( $50 \mathrm{mM} \mathrm{KCl}$ ) for 1-3 min, after which the dye was washed out. The fluorescence signal that was accumulated by recycled synaptic vesicles inside presynaptic terminals during intense synaptic activity remained clearly visible (Figure 5a). Equipped with this approach, we were able to visualize the FM1-43-mediated fluorescence related to numerous bouton-like structures, either on neuronal soma or along neurites, in hippocampal neurons of 1-week-old cultures (Figure 5b). This observation confirms the formation of functional (active) synapses in hippocampal neurons at the age of 7 days in vitro in the presence of NGF-loaded microcapsules. 


\section{Discussion}

The polyelectrolyte microcapsules fabricated by the LbL-technique have been demonstrated as an efficient delivery system for targeting different tissue and cell types. The suitability for this type of carriers has been confirmed in animals in vivo through either systemic application [44-47] or during local injections of the microcapsule suspension into the targeted tissue [24]. However, there have been only a few attempts to explore the use of biodegradable LbL-microcapsules in the central nervous system, especially with respect to the brain where multiple and distinct cell types are densely inter-connected with high spatial specificity. Therefore, our aim was to examine the potential of LbL-microcapsules for localised delivery of neurotrophins to central neurons, a potential tool to enhance guidance and formation of functional neuronal connections. This context differs from that of systemic application which envisages blood-brain barrier permeability followed by cell targeting.

Our strategy took advantage of the previous work in which fabrication protocols, release properties, and biodegradation in situ and in vivo for the LbL-fabricated microcapsules have been established $[12,23,24,33]$. Thus, the functional data obtained here in neuronal-astrocyte co-cultures, together with the previous reports pertaining to the encapsulation per se, suggest that LbL microcapsules meet the key requirements for applications targeting brain neurons. These include (i) high biocompatibility (no excitotoxicity) for all constitutive components of the microcapsule, (ii) gradual, prolonged release of the encapsulated compound of interest (including low molecular weight substances), and (iii) biodegradability (safe use). Monitoring primary hippocampal neurons in the present work has revealed no signs of excitotoxicity in the presence of microcapsules, at any stage of neuronal development and morphogenesis in vitro. Again, this is consistent with no effects of empty LbL-microcapsules (of the same composition) on primary hippocampal neurons or on peripheral nerve cells in vivo [24]. In addition, numerous studies have reported no toxicity produced by the LbL-microcapsules in other cell types of non-neuronal origin $[25,33,48-50]$.

The LbL technique of microcapsule fabrication enabled the encapsulation of NGF (a 13 kDa neuropeptide) using calcium carbonate particles as templates (for increasing the payload capacity, as validated previously [23,33]). NGF belongs to the superfamily of neurotrophins and has a diverse array of functions. These well-established properties include trophic effects and regulation of morphogenesis, such as guidance of nerve cell growth and axonal pathfinding, regulation of continued neurogenesis in the adult brain, and the activity-dependent network remodelling through establishing new synapses for synaptic transmission, plasticity, and neurocognitive functions [51,52]. This array of NGF actions involves regulated secretion by small amounts of NGF, which is followed by its cleavage, and subsequent direct or indirect actions of NGF molecules triggering intricate cell signalling cascades [53-55]. The morphogenic effects of encapsulated NGF on hippocampal neurons observed here include accelerated neuronal development, an increased neurite outgrowth rate and neurite branching: such effects have been well established, albeit without encapsulation, in the literature pertaining to the functional properties of NGF [56-59]. The capability to dictate the direction of neurite outgrowth involves the chemoattractive action of NGF molecules on the axonal growth cone: this action relies on the concentration gradients of NGF present in the surrounding medium. This gradient can vary from a minimum of $15 \mathrm{ng} \mathrm{mL}^{-1} \mathrm{~mm}^{-1}$ (required for directed neural progenitor cells navigation [60]), with a similar level for sensory axon guidance [61], to $133 \mathrm{ng} \mathrm{mL} \mathrm{mm}^{-1}$ (neurite outgrowth of PC12 cells [62]). However, there are threshold concentration values (above $995 \mathrm{ng} / \mathrm{mL}$ ) above which the NGF receptors become saturated, thus limiting successful neurites guidance [62]. The latter lends further support to the idea of having local, slow-releasing carriers to deliver neurotrophins, such as NGF, to brain neurons. Our data show the effects of encapsulated NGF mainly on neurons that occur at a relatively short distance $(<50 \mu \mathrm{m})$ from the NGF-loaded microcapsules or their clusters. This suggests that the slow NGF release generates a focal concentration gradient enabling a highly localised 
morphogenic action. These observations underline the advantage of the site-specific directional action of neurotrophins released at a low rate from microcapsules, as opposed to some other delivery strategies, such as, for instance, triggered cargo release with external stimuli (applied focused ultrasound, light, etc. [63,64]).

Here, the release kinetics of encapsulated NGF is expected to be similar to that of the supplementing protein (i.e., BSA), the feature that has been explored in some detail in our previous studies involving encapsulation of growth factors [23,33]. The release rates of fibroblast growth factor co-encapsulated with BSA have also been investigated by an independent group [32]. Taken together, these and other studies indicate that microcapsules based on the same polyelectrolytes as here (PArg and DS) provide a slow, prolonged (up to several days) release of growth factors, with a molecular weight similar to that of NGF, over several days. In terms of its neurobiological activity, NGF shows a fairly stable effect over at least an order of magnitude of its concentration in tissue [34,35], whereas the spatial location of microcapsules in tissue must dwarf other factors in setting the local NGF concentration gradient. These considerations allow for a wide range of NGF release rates to be relevant in the context of our experiments. As shown by our recent investigation [24], empty LbL-microcapsules of the same composite had no effect on electrophysiological properties of primary hippocampal neurons even when applied intracellularly. We therefore did not use empty-capsule control in the present study.

Emerging evidence suggests that neurotrophins have also been involved in directing axonal and dendritic arborization, formation of dendritic spines and functional synaptic connections, as well as release of neurotransmitters [65-67], which together shapes the architecture of neural networks in the adult. We found that encapsulated NGF promoted branching of neurites in local hippocampal neurons, which subsequently established functional synapses on neighbouring cells at a comparatively early stage in vitro. The exact regime of NGF delivery could play a key role in neuronal morphogenesis because diverse structural and functional effects have been found in hippocampal neurons upon different neuropeptide administration modes, favouring neurite branching and synaptic potentiation driven by gradual and sustained concentration increases, as opposed to fast and transient delivery of neurotrophins [68]. In addition, long-term exposure to exogenous neurotrophins was reported to augment excitatory transmission in hippocampal neurons [69].

The slow release of encapsulated NGF relies on the slowly progressing biodegradation of the microcapsule shells within the physiological environment. This can be monitored and adjusted for the relatively fast efflux of encapsulated NGF, as fast as between 6 and $24 \mathrm{~h}$ of incubation. The fabricated microcapsules used here are composed of biodegradable components only, such as poly-L-arginine (PArg) and dextran sulphate sodium salt, which are approved by the FDA and equivalent European regulatory authorities. Being biodegradable and inert, this type of carrier therefore has a fairly strong potential for its use in humans.

Depletion of endogenous NGF in the brain leads to severe neurodegeneration and is a cause of various brain disorders often associated with cognitive dysfunction $[1,2,70,71]$. Therefore, delivery of exogenous NGF to damaged brain regions followed by its relatively slow, long-lasting release could, in principle, trigger an alleviating effect. One approach to encapsulate NGF has utilized a W/O/W emulsification method [15], which resulted in the formation of larger $(>10 \mu \mathrm{m})$ capsules. The biodegradable poly (D, L-lactide-coglycolide) microspheres loaded with NGF completely degraded after three months of implantation in the intact striatum [15], suggesting safe use inside the brain. A similar NGF encapsulation strategy exploiting emulsification has been advocated to promote survival of cholinergic neurons: implantation of NGF-loaded microspheres into the brain improved spatial learning and memory in the rat model of Alzheimer's disease [72]. Nonetheless, the LbL-microcapsules seem to have certain advantages over microspheres, such as no cargo exposure to organic solvents, better tissue infiltration (due to a relatively smaller size), facilitated cargo loading, and manageable release properties. 


\section{Conclusions}

The present study provides experimental evidence for the morphogenic effects of the neuropeptide NGF, encapsulated inside biodegradable LbL-microcapsules, on primary hippocampal neurons. Our findings demonstrate, firstly, the applicability of this type of carriers for localized delivery of bioactive compounds, such as neurotrophins, to the environment of nerve cells. Secondly, they suggest that the targeted delivery of NGFloaded microcapsules has the potential to provide axonal guidance and synapse formation for central neurons during development. The key application strategy that we foresee for NGF-loaded capsules is not related to their systemic application or blood-brain barrier issues. We see the potential use of such microcapsules as a tool to help enable axonal outgrowth, trajectory guidance, and synapse formation among damaged or malformed nerve fibres in situ. We believe that it is by placing the capsules directly (via surgery or micro-injection) in the region(s) requiring axonal reconstruction, with high spatial precision, that the effect could be achieved. Clearly, further studies in vivo would be necessary to confirm the cargo system applicability in an intact brain.

Author Contributions: Conceptualization, D.A.R. and G.B.S.; methodology of LbL-microcapsules, A.M.P. and O.A.S.; methodology of neuronal cultures, O.K.; validation and formal analysis, O.K.; investigation, O.K.; resources and funding acquisition, D.A.R. and G.B.S.; writing-original draft, O.K.; writing-review and editing, D.A.R. and G.B.S. All authors have read and agreed to the published version of the manuscript.

Funding: This research was funded by the Biological Sciences Research Council grant 315 BB/J001473/1 (DAR and GBS); Wellcome Trust Principal Fellowship (212251_Z_18_Z), ERC Advanced Grant (323113), and European Commission NEUROTWIN grant (857562) (DAR).

Institutional Review Board Statement: All animal procedures were performed in accordance with the European Commission Directive 2010/63/EU (European Convention for the Protection of Vertebrate Animals used for Experimental and Other Scientific Purposes) and the UK Home Office (Scientific Procedures) Act (1986), UK Home Office Project Licence PPL P2E0141E1 and Ethics Committee, University College London.

Informed Consent Statement: Not applicable.

Data Availability Statement: Original data are available on request from the corresponding author.

Acknowledgments: The authors thank Marife Cano-Jaimez for the help with neuronal-astrocytic co-cultures.

Conflicts of Interest: The authors declare no conflict of interest. The funders had no role in the design of the study; in the collection, analyses, or interpretation of data; in the writing of the manuscript, or in the decision to publish the results.

$\begin{array}{ll}\text { Abbreviations } & \\ \text { BDNF } & \text { brain-derived neurotrophic facto } \\ \text { BSA } & \text { bovine serum albumin } \\ \text { DIC } & \text { differential interference contrast microscopy } \\ \text { DS } & \text { fluorescein isothiocyanate } \\ \text { FITC } & \text { N-(3-Triethylammoniumpropyl)-4-(4-(Dibutylamino) Styryl) Pyridinium Dibromide } \\ \text { FM1-43 dye } & \text { glial-cell-derived neurotrophic factor } \\ \text { GDNF } & \text { induced pluripotent stem cells } \\ \text { iPSC } & \text { high-potassium medium } \\ \text { KCl } & \text { layer-by-layer technique } \\ \text { LbL } & \text { nerve growth factor } \\ \text { NGF } & \text { poly-L-arginine } \\ \text { Parg } & \text { poly-lactic-co-glycolic-acid } \\ \text { PLGA } & \text { region of interest } \\ \text { ROI } & \text { scanning electron microscopy } \\ \text { SEM } & \text { standard error of the mean } \\ \text { s.e.m. } & \text { tetramethylrhodamine } \\ \text { TRITC } & \end{array}$




\section{References}

1. Autry, A.E.; Monteggia, L.M. Brain-derived neurotrophic factor and neuropsychiatric disorders. Pharmacol. Rev. 2012, 64, 238-258. [CrossRef] [PubMed]

2. Cirulli, F.; Alleva, E. The NGF saga: From animal models of psychosocial stress to stress-related psychopathology. Front. Neuroendocrinol. 2009, 30, 379-395. [CrossRef] [PubMed]

3. Tuszynski, M.H.; Blesch, A. Nerve growth factor: From animal models of cholinergic neuronal degeneration to gene therapy in Alzheimer's disease. Prog. Brain Res. 2004, 146, 441-449. [PubMed]

4. Nagahara, A.H.; Merrill, D.A.; Coppola, G.; Tsukada, S.; Schroeder, B.E.; Shaked, G.M.; Wang, L.; Blesch, A.; Kim, A.; Conner, J.M.; et al. Neuroprotective effects of brain-derived neurotrophic factor in rodent and primate models of Alzheimer's disease. Nat. Med. 2009, 15, 331-337. [CrossRef]

5. Nagahara, A.H.; Tuszynski, M.H. Potential therapeutic uses of BDNF in neurological and psychiatric disorders. Nat. Rev. Drug Discov. 2011, 10, 209-219. [CrossRef] [PubMed]

6. Hosseini, S.A.; Mohammadi, R.; Noruzi, S.; Mohamadi, Y.; Azizian, M.; Mousavy, S.M.; Ghasemi, F.; Hesari, A.; Sahebkar, A.; Salarinia, R.; et al. Stem cell- and gene-based therapies as potential candidates in Alzheimer's therapy. J. Cell. Biochem. 2018, 119, 8723-8736. [CrossRef] [PubMed]

7. Tuszynski, M.H.; Thal, L.; Pay, M.; Salmon, D.P.; U, H.S.; Bakay, R.; Patel, P.; Blesch, A.; Vahlsing, H.L.; Ho, G.; et al. A phase 1 clinical trial of nerve growth factor gene therapy for Alzheimer disease. Nat. Med. 2005, 11, 551-555. [CrossRef] [PubMed]

8. Tuszynski, M.H.; Yang, J.H.; Barba, D.; U, H.S.; Bakay, R.A.; Pay, M.M.; Masliah, E.; Conner, J.M.; Kobalka, P.; Roy, S.; et al. Nerve Growth Factor Gene Therapy: Activation of Neuronal Responses in Alzheimer Disease. JAMA Neurol. 2015, 72, 1139-1147. [CrossRef]

9. Lindvall, O.; Wahlberg, L.U. Encapsulated cell biodelivery of GDNF: A novel clinical strategy for neuroprotection and neuroregeneration in Parkinson's disease? Exp. Neurol. 2008, 209, 82-88. [CrossRef]

10. Winn, S.R.; Lindner, M.D.; Lee, A.; Haggett, G.; Francis, J.M.; Emerich, D.F. Polymer-encapsulated genetically modified cells continue to secrete human nerve growth factor for over one year in rat ventricles: Behavioral and anatomical consequences. Exp. Neurol. 1996, 140, 126-138. [CrossRef]

11. Fjord-Larsen, L.; Kusk, P.; Emerich, D.F.; Thanos, C.; Torp, M.; Bintz, B.; Tornoe, J.; Johnsen, A.H.; Wahlberg, L.U. Increased encapsulated cell biodelivery of nerve growth factor in the brain by transposon-mediated gene transfer. Gene Ther. 2012, 19, 1010-1017. [CrossRef]

12. He, H.; Luedke, E.; Zhang, X.; Yu, B.; Schmitt, A.; McClarren, B.; Grignol, V.; Carson, W.E., 3rd; Lee, L.J. A naonoporous cell-therapy device with controllable biodegradation for long-term drug release. J. Control. Release 2013, 165, 226-233. [CrossRef] [PubMed]

13. Wahlberg, L.U.; Lind, G.; Almqvist, P.M.; Kusk, P.; Tornoe, J.; Juliusson, B.; Soderman, M.; Sellden, E.; Seiger, A.; EriksdotterJonhagen, M.; et al. Targeted delivery of nerve growth factor via encapsulated cell biodelivery in Alzheimer disease: A technology platform for restorative neurosurgery. J. Neurosurg. 2012, 117, 340-347. [CrossRef] [PubMed]

14. de Boer, R.; Knight, A.M.; Spinner, R.J.; Malessy, M.J.; Yaszemski, M.J.; Windebank, A.J. In vitro and in vivo release of nerve growth factor from biodegradable poly-lactic-co-glycolic-acid microspheres. J. Biomed. Mater. Res. A 2010, 95, 1067-1073. [CrossRef] [PubMed]

15. Menei, P.; Pean, J.M.; Nerriere-Daguin, V.; Jollivet, C.; Brachet, P.; Benoit, J.P. Intracerebral implantation of NGF-releasing biodegradable microspheres protects striatum against excitotoxic damage. Exp. Neurol. 2000, 161, 259-272. [CrossRef] [PubMed]

16. de Boer, R.; Borntraeger, A.; Knight, A.M.; Hebert-Blouin, M.N.; Spinner, R.J.; Malessy, M.J.; Yaszemski, M.J.; Windebank, A.J. Short- and long-term peripheral nerve regeneration using a poly-lactic-co-glycolic-acid scaffold containing nerve growth factor and glial cell line-derived neurotrophic factor releasing microspheres. J. Biomed. Mater. Res. Part A 2012, 100, $2139-2146$. [CrossRef]

17. Santos, D.; Giudetti, G.; Micera, S.; Navarro, X.; del Valle, J. Focal release of neurotrophic factors by biodegradable microspheres enhance motor and sensory axonal regeneration in vitro and in vivo. Brain Res. 2016, 1636, 93-106. [CrossRef]

18. Mili, B.; Das, K.; Kumar, A.; Saxena, A.C.; Singh, P.; Ghosh, S.; Bag, S. Preparation of NGF encapsulated chitosan nanoparticles and its evaluation on neuronal differentiation potentiality of canine mesenchymal stem cells. J. Mater. Sci. Mater. Med. 2017, 29, 4. [CrossRef]

19. Rajam, M.; Pulavendran, S.; Rose, C.; Mandal, A.B. Chitosan nanoparticles as a dual growth factor delivery system for tissue engineering applications. Int. J. Pharm. 2011, 410, 145-152. [CrossRef]

20. Habraken, W.J.; Boerman, O.C.; Wolke, J.G.; Mikos, A.G.; Jansen, J.A. In vitro growth factor release from injectable calcium phosphate cements containing gelatin microspheres. J. Biomed. Mater. Res. A 2009, 91, 614-622. [CrossRef]

21. Kim, S.Y.; Hwang, J.Y.; Shin, U.S. Preparation of nano/macroporous polycaprolactone microspheres for an injectable cell delivery system using room temperature ionic liquid and camphene. J. Colloid Interface Sci. 2016, 465, 18-25. [CrossRef] [PubMed]

22. Kraskiewicz, H.; Breen, B.; Sargeant, T.; McMahon, S.; Pandit, A. Assembly of protein-based hollow spheres encapsulating a therapeutic factor. ACS Chem. Neurosci. 2013, 4, 1297-1304. [CrossRef] [PubMed]

23. She, Z.; Antipina, M.N.; Li, J.; Sukhorukov, G.B. Mechanism of protein release from polyelectrolyte multilayer microcapsules. Biomacromolecules 2010, 11, 1241-1247. [CrossRef] [PubMed] 
24. Kopach, O.; Zheng, K.; Dong, L.; Sapelkin, A.; Voitenko, N.; Sukhorukov, G.B.; Rusakov, D.A. Nano-engineered microcapsules boost the treatment of persistent pain. Drug Deliv. 2018, 25, 435-447. [CrossRef] [PubMed]

25. Timin, A.S.; Muslimov, A.R.; Lepik, K.V.; Epifanovskaya, O.S.; Shakirova, A.I.; Mock, U.; Riecken, K.; Okilova, M.V.; Sergeev, V.S.; Afanasyev, B.V.; et al. Efficient gene editing via non-viral delivery of CRISPR-Cas9 system using polymeric and hybrid microcarriers. Nanomedicine 2018, 14, 97-108. [CrossRef]

26. Balabushevitch, N.G.; Sukhorukov, G.B.; Moroz, N.A.; Volodkin, D.V.; Larionova, N.I.; Donath, E.; Mohwald, H. Encapsulation of proteins by layer-by-layer adsorption of polyelectrolytes onto protein aggregates: Factors regulating the protein release. Biotechnol. Bioeng. 2001, 76, 207-213. [CrossRef]

27. Shenoy, D.B.; Antipov, A.A.; Sukhorukov, G.B.; Möhwald, H. Layer-by-layer engineering of biocompatible, decomposable core-shell structures. Biomacromolecules 2003, 4, 265-272. [CrossRef]

28. Stuart, M.A.; Huck, W.T.; Genzer, J.; Muller, M.; Ober, C.; Stamm, M.; Sukhorukov, G.B.; Szleifer, I.; Tsukruk, V.V.; Urban, M.; et al. Emerging applications of stimuli-responsive polymer materials. Nat. Mater. 2010, 9, 101-113. [CrossRef]

29. Sukhorukov, G.B.; Mohwald, H. Multifunctional cargo systems for biotechnology. Trends Biotechnol. 2007, 25, 93-98. [CrossRef]

30. Zhu, X.H.; Wang, C.H.; Tong, Y.W. In vitro characterization of hepatocyte growth factor release from PHBV/PLGA microsphere scaffold. J. Biomed. Mater. Res. A 2009, 89, 411-423. [CrossRef]

31. Wang, J.; Sun, B.; Tian, L.; He, X.; Gao, Q.; Wu, T.; Ramakrishna, S.; Zheng, J.; Mo, X. Evaluation of the potential of rhTGF- beta3 encapsulated P(LLA-CL)/collagen nanofibers for tracheal cartilage regeneration using mesenchymal stems cells derived from Wharton's jelly of human umbilical cord. Mater. Sci Eng. C Mater. Biol. Appl. 2017, 70, 637-645. [CrossRef] [PubMed]

32. She, Z.; Wang, C.; Li, J.; Sukhorukov, G.B.; Antipina, M.N. Encapsulation of basic fibroblast growth factor by polyelectrolyte multilayer microcapsules and its controlled release for enhancing cell proliferation. Biomacromolecules 2012, 13, $2174-2180$. [CrossRef] [PubMed]

33. Lomova, M.V.; Brichkina, A.I.; Kiryukhin, M.V.; Vasina, E.N.; Pavlov, A.M.; Gorin, D.A.; Sukhorukov, G.B.; Antipina, M.N Multilayer Capsules of Bovine Serum Albumin and Tannic Acid for Controlled Release by Enzymatic Degradation. ACS Appl. Mater. Interfaces 2015, 7, 11732-11740. [CrossRef] [PubMed]

34. Sofroniew, M.V.; Howe, C.L.; Mobley, W.C. Nerve growth factor signaling, neuroprotection, and neural repair. Annu. Rev. Neurosci. 2001, 24, 1217-1281. [CrossRef]

35. Aloe, L.; Rocco, M.L.; Bianchi, P.; Manni, L. Nerve growth factor: From the early discoveries to the potential clinical use. J. Transl. Med. 2012, 10, 239. [CrossRef]

36. Henneberger, C.; Bard, L.; Panatier, A.; Reynolds, J.P.; Kopach, O.; Medvedev, N.I.; Minge, D.; Herde, M.K.; Anders, S.; Kraev, I.; et al. LTP Induction Boosts Glutamate Spillover by Driving Withdrawal of Perisynaptic Astroglia. Neuron 2020, 108, 919-936.e911. [CrossRef]

37. Jensen, T.P.; Zheng, K.Y.; Cole, N.; Marvin, J.S.; Looger, L.L.; Rusakov, D.A. Multiplex imaging relates quantal glutamate release to presynaptic Ca2+ homeostasis at multiple synapses in situ. Nat. Commun. 2019, 10, 1414. [CrossRef]

38. Craig, A.M.; Banker, G. Neuronal polarity. Annu. Rev. Neurosci. 1994, 17, 267-310. [CrossRef]

39. Ermolyuk, Y.S.; Alder, F.G.; Henneberger, C.; Rusakov, D.A.; Kullmann, D.M.; Volynski, K.E. Independent regulation of basal neurotransmitter release efficacy by variable $\mathrm{Ca}^{2+}$ influx and bouton size at small central synapses. PLoS Biol. 2012, 10, e1001396. [CrossRef]

40. Gaffield, M.A.; Betz, W.J. Imaging synaptic vesicle exocytosis and endocytosis with FM dyes. Nat. Protoc. 2006, 1, $2916-2921$. [CrossRef]

41. Jareb, M.; Banker, G. Inhibition of axonal growth by brefeldin A in hippocampal neurons in culture. J. Neurosci. 1997, 17, 8955-8963. [CrossRef] [PubMed]

42. Brann, A.B.; Scott, R.; Neuberger, Y.; Abulafia, D.; Boldin, S.; Fainzilber, M.; Futerman, A.H. Ceramide signaling downstream of the p75 neurotrophin receptor mediates the effects of nerve growth factor on outgrowth of cultured hippocampal neurons. J. Neurosci. Off. J. Soc. Neurosci. 1999, 19, 8199-8206. [CrossRef]

43. Novak, P.; Gorelik, J.; Vivekananda, U.; Shevchuk, A.I.; Ermolyuk, Y.S.; Bailey, R.J.; Bushby, A.J.; Moss, G.W.; Rusakov, D.A.; Klenerman, D.; et al. Nanoscale-targeted patch-clamp recordings of functional presynaptic ion channels. Neuron 2013, 79, 1067-1077. [CrossRef] [PubMed]

44. Kupikowska-Stobba, B.; Lewinska, D. Polymer microcapsules and microbeads as cell carriers for in vivo biomedical applications. Biomater. Sci. 2020, 8, 1536-1574. [CrossRef]

45. Mayorova, O.A.; Sindeeva, O.A.; Lomova, M.V.; Gusliakov, O.I.; Tarakanchikova, Y.V.; Tyutyaev, E.V.; Pinyaev, S.I.; Kulikov, O.A.; German, S.V.; Pyataev, N.A.; et al. Endovascular addressing improves the effectiveness of magnetic targeting of drug carrier. Comparison with the conventional administration method. Nanomed. Nanotechnol. Biol. Med. 2020, 102184. [CrossRef]

46. Navolokin, N.A.; German, S.V.; Bucharskaya, A.B.; Godage, O.S.; Zuev, V.V.; Maslyakova, G.N.; Pyataev, N.A.; Zamyshliaev, P.S.; Zharkov, M.N.; Terentyuk, G.S.; et al. Systemic Administration of Polyelectrolyte Microcapsules: Where Do They Accumulate and When? In Vivo and Ex Vivo Study. Nanomaterials 2018, 8, 812. [CrossRef]

47. Novoselova, M.V.; German, S.V.; Sindeeva, O.A.; Kulikov, O.A.; Minaeva, O.V.; Brodovskaya, E.P.; Ageev, V.P.; Zharkov, M.N.; Pyataev, N.A.; Sukhorukov, G.B.; et al. Submicron-Sized Nanocomposite Magnetic-Sensitive Carriers: Controllable Organ Distribution and Biological Effects. Polymers 2019, 11, 1082. [CrossRef] 
48. Pavlov, A.M.; Sapelkin, A.V.; Huang, X.; P’Ng K, M.; Bushby, A.J.; Sukhorukov, G.B.; Skirtach, A.G. Neuron cells uptake of polymeric microcapsules and subsequent intracellular release. Macromol. Biosci. 2011, 11, 848-854. [CrossRef]

49. Timin, A.S.; Muslimov, A.R.; Petrova, A.V.; Lepik, K.V.; Okilova, M.V.; Vasin, A.V.; Afanasyev, B.V.; Sukhorukov, G.B. Hybrid inorganic-organic capsules for efficient intracellular delivery of novel siRNAs against influenza A (H1N1) virus infection. Sci. Rep. 2017, 7, 102. [CrossRef]

50. Ribeiro, C.; Borges, J. Preparation of Well-Dispersed Chitosan/Alginate Hollow Multilayered Microcapsules for Enhanced Cellular Internalization. Molecules 2018, 23, 625. [CrossRef]

51. Kumar, A.; Pareek, V.; Faiq, M.A.; Kumar, P.; Raza, K.; Prasoon, P.; Dantham, S.; Mochan, S. Regulatory role of NGFs in neurocognitive functions. Rev. Neurosci. 2017, 28, 649-673. [CrossRef] [PubMed]

52. Schinder, A.F.; Poo, M. The neurotrophin hypothesis for synaptic plasticity. Trends Neurosci. 2000, 23, 639-645. [CrossRef]

53. Levi-Montalcini, R. The nerve growth factor 35 years later. Science 1987, 237, 1154-1162. [CrossRef]

54. Meakin, S.O.; Shooter, E.M. The nerve growth factor family of receptors. Trends Neurosci. 1992, 15, 323-331. [CrossRef]

55. Ascano, M.; Bodmer, D.; Kuruvilla, R. Endocytic trafficking of neurotrophins in neural development. Trends Cell Biol. 2012, 22, 266-273. [CrossRef] [PubMed]

56. Secondo, A.; Esposito, A.; Sirabella, R.; Boscia, F.; Pannaccione, A.; Molinaro, P.; Cantile, M.; Ciccone, R.; Sisalli, M.J.; Scorziello, A.; et al. Involvement of the $\mathrm{Na}+/ \mathrm{Ca} 2+$ exchanger isoform 1 (NCX1) in neuronal growth factor (NGF)-induced neuronal differentiation through Ca2+-dependent Akt phosphorylation. J. Biol. Chem. 2015, 290, 1319-1331. [CrossRef] [PubMed]

57. Selvaraj, P.; Huang, J.S.; Chen, A.; Skalka, N.; Rosin-Arbesfeld, R.; Loh, Y.P. Neurotrophic factor-alpha1 modulates NGF-induced neurite outgrowth through interaction with Wnt-3a and Wnt-5a in PC12 cells and cortical neurons. Mol. Cell. Neurosci. 2015, 68, 222-233. [CrossRef]

58. Sato, Y.; Suzuki, S.; Kitabatake, M.; Hara, T.; Kojima, M. Generation of TrkA/TrkB chimeric receptor constructs reveals molecular mechanisms underlying BDNF-induced dendritic outgrowth in hippocampal neurons. Cell. Mol. Neurobiol. 2011, 31, 605-614. [CrossRef]

59. Tatebayashi, Y.; Haque, N.; Tung, Y.C.; Iqbal, K.; Grundke-Iqbal, I. Role of tau phosphorylation by glycogen synthase kinase-3beta in the regulation of organelle transport. J. Cell Sci. 2004, 117, 1653-1663. [CrossRef]

60. Shamloo, A.; Heibatollahi, M.; Mofrad, M.R. Directional migration and differentiation of neural stem cells within threedimensional microenvironments. Integr. Biol. Quant. Biosci. Nano Macro 2015, 7, 335-344. [CrossRef]

61. Curley, J.L.; Catig, G.C.; Horn-Ranney, E.L.; Moore, M.J. Sensory axon guidance with semaphorin 6A and nerve growth factor in a biomimetic choice point model. Biofabrication 2014, 6, 035026. [CrossRef] [PubMed]

62. Cao, X.; Shoichet, M.S. Defining the concentration gradient of nerve growth factor for guided neurite outgrowth. Neuroscience 2001, 103, 831-840. [CrossRef]

63. Munoz Javier, A.; del Pino, P.; Bedard, M.F.; Ho, D.; Skirtach, A.G.; Sukhorukov, G.B.; Plank, C.; Parak, W.J. Photoactivated release of cargo from the cavity of polyelectrolyte capsules to the cytosol of cells. Langmuir ACS J. Surf. Colloids 2008, 24, 12517-12520. [CrossRef] [PubMed]

64. Tanbour, R.; Martins, A.M.; Pitt, W.G.; Husseini, G.A. Drug Delivery Systems Based on Polymeric Micelles and Ultrasound: A Review. Curr. Pharm. Des. 2016, 22, 2796-2807. [CrossRef] [PubMed]

65. Armijo-Weingart, L.; Ketschek, A.; Sainath, R.; Pacheco, A.; Smith, G.M.; Gallo, G. Neurotrophins induce fission of mitochondria along embryonic sensory axons. eLife 2019, 8. [CrossRef] [PubMed]

66. Cohen-Cory, S. BDNF modulates, but does not mediate, activity-dependent branching and remodeling of optic axon arbors in vivo. J. Neurosci. Off. J. Soc. Neurosci. 1999, 19, 9996-10003. [CrossRef]

67. Conner, J.M.; Franks, K.M.; Titterness, A.K.; Russell, K.; Merrill, D.A.; Christie, B.R.; Sejnowski, T.J.; Tuszynski, M.H. NGF is essential for hippocampal plasticity and learning. J. Neurosci. 2009, 29, 10883-10889. [CrossRef]

68. Ji, Y.; Lu, Y.; Yang, F.; Shen, W.; Tang, T.T.; Feng, L.; Duan, S.; Lu, B. Acute and gradual increases in BDNF concentration elicit distinct signaling and functions in neurons. Nat. Neurosci. 2010, 13, 302-309. [CrossRef]

69. Rauti, R.; Cellot, G.; D’Andrea, P.; Colliva, A.; Scaini, D.; Tongiorgi, E.; Ballerini, L. BDNF impact on synaptic dynamics: Extra or intracellular long-term release differently regulates cultured hippocampal synapses. Mol. Brain 2020, 13, 43. [CrossRef]

70. Berton, O.; McClung, C.A.; Dileone, R.J.; Krishnan, V.; Renthal, W.; Russo, S.J.; Graham, D.; Tsankova, N.M.; Bolanos, C.A.; Rios, M.; et al. Essential role of BDNF in the mesolimbic dopamine pathway in social defeat stress. Science 2006, 311, 864-868. [CrossRef]

71. Fahnestock, M.; Michalski, B.; Xu, B.; Coughlin, M.D. The precursor pro-nerve growth factor is the predominant form of nerve growth factor in brain and is increased in Alzheimer's disease. Mol. Cell. Neurosci. 2001, 18, 210-220. [CrossRef] [PubMed]

72. Gu, H.; Long, D.; Song, C.; Li, X. Recombinant human NGF-loaded microspheres promote survival of basal forebrain cholinergic neurons and improve memory impairments of spatial learning in the rat model of Alzheimer's disease with fimbria-fornix lesion. Neurosci. Lett. 2009, 453, 204-209. [CrossRef] [PubMed] 